\title{
Research on University Students' academic procrastination behavior and Countermeasures
}

\author{
Haiyan Liu ${ }^{\text {a }}$, Jingju Hou ${ }^{\text {b }}$ \\ Information Technology Institute, Jilin Agricultural University, Changchun 130117, China \\ ahaiyan_49@sohu.com, bzzjj18zz@sina.com
}

\begin{abstract}
Academic procrastination is a very common phenomenon in the life of the college students' learning, the 228 Jilin Agricultural University students issued a "questionnaire of the college students' academic procrastination situation", and in accordance with the grade and gender results were compared and discussed the reasons of Academic Procrastination of college students, and puts forward the Countermeasures of college students the delay problem, to alleviate or reduce the degree of academic procrastination, and provide the basis for the development of university administrators to better grasp and guide student.
\end{abstract}

Keywords: College students; Academic procrastination; Procrastination.

\section{Introduction}

Academic procrastination is a common problem among the students, especially in the special group of college students. Procrastination, that limited time range to avoid or postpone the academic task until the deadline approaching began to proceed with the behavior, such behavior may lead to bad learning result and negative learning experience, will let the individual produce negative emotional experience. Entered the stage of university and college students learning style from "teaching and learning" to "self-study" give priority to, at the mercy of the time in learning, learning plan arrangement, the aim of obtaining and learning tasks are very different from high school, the determination of its autonomy is higher, and is common among college students of procrastination for individual learning habits, learning attitude, learning and personality training will have a negative impact.

Therefore, the students' academic procrastination and cause investigation and analysis, can be more detailed and comprehensive understanding of the college students' academic procrastination, and puts forward some corresponding academic procrastination solution of the problem.

\section{University students' academic procrastination status quo of the research}

In this paper, some college students in Jilin Agricultural University as the research object, a total of 260 questionnaires were issued, 255 were recovered, the recovery rate was 228 , and the effective questionnaires were $98 \%$. According to the causes of College Students' learning and life practice and academic procrastination, the preliminary screening of the problem, completed the preparation of the questionnaire. The questionnaire include 36 problems, measuring the delay condition of students in six kinds of tasks, the six task of writing respectively semester or course work, review the reference appendix, weekly academic tasks, to participate in the schools, departments, or class assignments, and other learning plan (such as English four, six levels of tests), read books from other people or library. The six tasks are very close to the usual study life, can let the participants' college students from their own consider their procrastination in the six academic tasks. After investigations of six kinds of academic tasks for participants from frequency, delay of degree, want to change the delay is the desire to assess these three aspects, by five points: never delay, 1 minute. There is almost no delay, 2; Procrastinate, 3; Often procrastination, 4 points; Always delay, 5 points. In Howell, Watson's study, will be the research object and whether the delay frequency scores of two aspects of a problem as the degree of academic procrastination total score, the higher the score shows that the more serious delay, in order to scale the number to distinguish between points, total academic procrastination scored 36 or more is considered academic procrastinators, and $<36$ points are procrastinators, a score of 6 or 
more in each academic tasks is considered in the task of academic procrastination, and $<6$ can be thought of in the academic task does not exist in the academic procrastination, this research is still using this definition.

\subsection{Object of study.}

In this paper, some college students in Jilin Agricultural University as the research object, a total of 260 points, 255 points, the recovery rate is $98 \%$, the effective questionnaire 228 , the survey results as shown in Table 1.

Table. 1 Effective sample subjects

\begin{tabular}{cccc}
\hline & Level & Frequency & Proportion \\
\hline \multirow{2}{*}{ Gender } & Male & 109 & $47.80 \%$ \\
& Female & 119 & $52.20 \%$ \\
\multirow{3}{*}{ Education } & Undergraduate & 205 & $89.91 \%$ \\
& Graduate student & 23 & $10.09 \%$ \\
\multirow{2}{*}{ Major } & Science and engineering & 105 & $46.05 \%$ \\
& Liberal arts & 123 & $53.95 \%$ \\
\hline
\end{tabular}

\subsection{Data investigation and analysis.}

(1) Academic delay of differences in gender, grade, professional

a) Academic procrastination gender differences, girls' degree of academic procrastination is more serious than boys. b) As a whole, with the increase of students' grade, the degree of academic procrastination aggravate gradually, among them, the most serious degree of junior students' academic procrastination. The graduate student's delay is far lower than undergraduates. c) On the whole, the liberal arts class specialized students' academic procrastination degree above major in science and engineering students.

(2) Delay degree analyses

a) Often or always delay proportion. Questionnaire of each task of the first question, is the task of subjects delay the frequency of inspection, the results showed that six academic activities, the choice of 1 in each task "often delay" or "stall" proportion of the number of statistical results from high to low in turn is: write the semester or course work $(75.87 \%)$, review the reference appendix $(52.19 \%)$, reading from others or library books $(50.43 \%)$, weekly school assignments $(45.17 \%)$, participate in the school faculty or class assignments (42.98\%), other study plan (35.08\%). As shown in table 2.

Table 2 academic procrastination in six academic tasks

\begin{tabular}{ccc}
\hline Academic task & $\begin{array}{c}\text { The number of } \\
\text { academic } \\
\text { procrastination }\end{array}$ & $\begin{array}{c}\text { The proportion } \\
\text { of the total }\end{array}$ \\
\hline Writing a term or course paper & 173 & 75.87 \\
Review preparation & 169 & 52.19 \\
Complete weekly academic task & 103 & 45.17 \\
Participate in the schools, departments, or class assignments & 98 & 42.98 \\
Other learning programs & 80 & 35.08 \\
Read books from other people or library & 115 & 50.43 \\
\hline
\end{tabular}

b) The proportion of the number of people who often or always becomes a problem. Questionnaire for each task of the second question, examines the participants is the delay on this task for the participants is in trouble. The results showed that six academic activities, the choice of the second question in each task "often" or "always" the proportion of research results from high to low in turn is: write the semester or course work $(52.00 \%)$, reading from others or library books $(49.10 \%)$, weekly review academic assignments $(38.14 \%)$, for reference $(33.09 \%)$, other learning plan $(29.24 \%)$, to participate in school faculty or class assignments $(22.32 \%)$.

c) College students want to reduce the number of delays in the proportion of the number of. Third questions on each task of the questionnaire were examined, and the degree of desire to alter the 
behavior of procrastination on this task was examined. Answer using a 5 score, 1 for "never thought", 2 for "very little", 3 for "sometimes thought", 4 for "most of the time," 5 for "absolutely". The results show that the six academic activities, third multiple-choice "under each task of statistical results of most of the time to" or "absolute thought" proportion from high to low is as follows: $(79.01 \%)$ the pro forma review, weekly academic operations (72.82\%), writing or learning course papers (68.92\%) and other learning plan (61.90\%), complete the school faculty or class do not know the task $(54.08 \%)$, reading borrowed from others or library books $(43.66 \%)$.

\section{To improve college students learning procrastination countermeasures}

Academic procrastination will not only harm the university students' study, but also harm the students' learning mood and emotion. Although some students can be aware of the consequences of academic procrastination will affect their learning quality, wasting their time, so that they have negative emotions, but no one students realize that they have serious consequences of academic procrastination and physical damage. Based on delay influence on college students' learning, puts forward the following countermeasures of learning procrastination.

\subsection{Changing college Students' incorrect cognition.}

According to the $\mathrm{ABC}$ theory, the negative emotions are produced because of irrational cognition, which shows that the students' learning tasks are not healthy and not correct. Some students believe that their professional and future employment has nothing to do, so the study of professional courses is a waste of time, there are students that he chose the profession is not what they like, and so on. This poor cognition is often the students' understanding of the current learning and curriculum. Therefore, if you want to change the Procrastination of college students learning, we must first change the students' awareness, understanding of their attitudes and perceptions, and targeted to correct, eliminate students' aversion.

\subsection{Strengthen the education of College Students' time management}

Some foreign scholars of the time management of the poor college students carry out a psychological treatment model, the main function of this model is to increase the delay of self-control ability, improve self-value, and enhance the self-sense of power delay. College managers can accord this model to help students establish a correct concept of time, reasonable and full use of our time in the best time to study, at the end of the effective time task, to achieve effective self-management consciously.

\subsection{Psychological counseling for college students}

Many studies have shown that excessive self-esteem, demanding perfectionist, personality traits, unstable emotion psychology and learning procrastination has certain relevance, and therefore, we should start from the Angle of psychology students delay cause of comprehensive analysis, on the personality psychological characteristics of the students' psychological counseling, to help students overcome procrastination, out of the psychological dilemma.

\subsection{Improving college students' Self-efficacy}

Self-efficacy is the subjective judgment and evaluation of an individual's ability to accomplish a task or activity successfully. Academic self-efficacy, as a specific embodiment of self-efficacy in the study area, is divided into two dimensions: learning ability self-efficacy and learning behavior self-efficacy. Self-efficacy of learning ability refers to the ability of students to successfully complete their academic tasks, to obtain excellent academic achievement and to avoid the failure of learning ability evaluation and judgment. Self-efficacy of learning behavior refers to the assessment and judgment of students' individual ability through their own learning methods in order to achieve their academic requirements. Because of lack of confidence in the face of students of academic procrastination, the most important is to enhance students' self-efficacy; students can have confidence in the face of the learning task, when things done can be more a sense of competence.

\subsection{Play the group function}

The group effect play in the role of college students is very great, facing the procrastination of college students, we can supervise power groups to supervise them to finish their tasks such as the 
establishment of different study groups, implementation of group supervision and group competition, can also use social media now popular such as WeChat QQ and other supervision.

College students are the hope of the nation, is the backbone of the cause of social progress, in the revival of the nation is essential, but the academic procrastination seriously affects the physical and mental health of college students, seriously hindered their creativity and learning ability, we should on the academic procrastination of college students to attach great importance to strengthen the research on delay theory, pay attention to the cultivation of their solution of academic procrastination, help them out of academic procrastination problems, cultivate social needs, healthy body and mind, do a longer Academic Procrastination of College students.

\section{Conclusion}

To solve the academic procrastination of college students, can be improved from two aspects of college students and the school, the first students must establish more positive learning and life, learn to make reasonable and complete plan, and constantly improve their supervision and plans to complete the situation. At the same time, the school should pay attention to the establishment of a good learning atmosphere and cultural atmosphere, the students' procrastination behavior for targeted management and guidance.

\section{Acknowledgments}

This work was financially supported by Jilin Agricultural University undergraduate science and Technology Innovation Fund, Project name: College students rely on social media and academic procrastination research.

\section{References}

[1] Tiantian Wang, Lili Tian, Shi Yu, et al. Research on University Students' academic procrastination behavior and Countermeasures. Journal of Higher Education. (2016) No. 10, p. $167-168$

[2] Chengling Hua, Yuru Han, Xiaoqin Xu g et al. Investigation and Research on College Students' academic procrastination and its causes. Education Teaching Forum. (2016) No.46, p.5-7.

[3] Qiang Li. Research on the academic procrastination of College Students. Journal of Hubei Correspondence University. Vol. 27 (2014) No.16, p.24-25. 